\title{
Prevalência de anticorpos contra os vírus da influenza, da arterite viral e herpesvírus em eqüinos do Estado do Rio Grande do Sul, Brasil
}

\author{
Prevalence of antibodies to influenza virus, viral arteritis and herpesvirus in horses of the \\ Rio Grande do Sul state, Brazil
}

\author{
Diego Gustavo Diel ${ }^{1}$ Sabrina Ribeiro de Almeida ${ }^{1}$ Rudi Weiblen $^{2}$ Rafael Frandoloso $^{3}$ \\ Denis Anziliero $^{3}$ Luiz Carlos Kreutz ${ }^{3}$ Fernando Henrique Sauter Groff ${ }^{4}$ \\ Eduardo Furtado Flores ${ }^{2 *}$
}

\section{RESUMO}

O presente estudo teve como objetivo determinar a prevalência de anticorpos contra os vírus da influenza (EIV), da arterite viral (EVAV) e herpesvírus (EHV) em eqüinos no Estado do Rio Grande do Sul (RS), Brasil. Amostras de soro provenientes de eqüinos de 65 municípios do Estado foram submetidas ao teste de inibição da hemaglutinação (HI) para a pesquisa de anticorpos contra o EIV, e à técnica de soroneutralização (SN), para a detecção de anticorpos contra os vírus da EVA e da EHV. Das 1.506 amostras testadas, 986 $(65,4 \%)$ apresentaram anticorpos para o EIV (títulos entre 10 e 1280), 33 (2,2\%) para o EVAV (2-16) e 67 (4,5\%) foram positivas para o EHV (2-64). Dentre os 65 municípios amostrados, 55 (84,6\%) apresentaram pelo menos um animal positivo para o EIV, 15 (23\%) para o EVAV e 12 (18,5\%) para o EHV. A prevalência de anticorpos para cada vírus não variou muito entre animais de diferentes propósitos (esporte, exposição e reprodução) e entre machos e fêmeas, indicando que os diferentes sistemas de criação apresentam condições epidemiológicas semelhantes em relação a essas infecções. Os resultados obtidos sugerem a circulação desses agentes na população eqüina do RS e alertam para a necessidade de estudos adicionais sobre a importância e o impacto econômicosanitário dessas viroses para a eqüideocultura do Estado.

Palavras-chave: soroprevalência, epidemiologia, EIV, EVAV, EHV.

\section{ABSTRACT}

This study was aimed at investigating the prevalence of antibodies against, influenza virus (EIV), equine viral arteritis virus (EVAV), and herpesvirus (EHV) among horses in Rio Grande do Sul (RS) state, Brazil. Serum samples from horses of 65 counties of northern and northwestern RS, were tested by inhibition hemaglutination test (HI) for EIV and by virusneutralization test (VN) for EVAV and EHV antibodies. From 1506 samples, 986 (65.4\%) had antibodies to EIV (titers ranging from 10 to 1280$), 33$ (2.2\%) were positive to EVAV antibodies (2-16), and 67 (4.5\%) for EHV (2-64). Among the 65 counties, 55 (84.6\%) presented at least one positive animal to EIV, 15 (23\%) to EVAV, and 12 (18.5\%) to EHV. The prevalence among horses of different purposes (sports, farmshow and reproduction), and between genders did not differ significantly, indicating that these herds are epidemiologically similar regarding to these infections. These results demonstrate the presence of these agents among $R S$ horses and indicate the need for additional epidemiological studies to determine the sanitary and economical importance of these infections for the State equine husbandry.

Key words: seroprevalence, epidemiology, EIV, EVAV, EHV.

\section{INTRODUÇÃO}

A eqüideocultura constitui importante segmento do agronegócio brasileiro. Além de sua ligação com a pecuária comercial, a atividade possui uma forte inter-relação com setores ligados ao lazer, à

\footnotetext{
${ }^{1}$ Programa de Pós-graduação em Medicina Veterinária (PPGMV), Universidade Federal de Santa Maria (UFSM), Santa Maria, RS, Brasil.

${ }^{2}$ Departamento de Medicina Veterinária Preventiva (DMVP), Centro de Ciências Rurais (CCR), Setor de Virologia (SV), UFSM, 97105-900, Santa Maria, RS, Brasil. E-mail: flores@ccr.ufsm.br. Fone/fax: 55-3220-8034. *Autor para correspondência.

${ }^{3}$ Faculdade de Agronomia e Medicina Veterinária, Laboratório de Virologia e Imunologia, Universidade de Passo Fundo (UPF), Passo Fundo, RS, Brasil.

${ }^{4}$ Divisão de Fiscalização e Defesa Sanitária Animal da Secretaria da Agricultura do RS, Porto Alegre, Brasil.
} 
cultura, ao esporte e ao ecoturismo. O Brasil possui o terceiro maior rebanho eqüino do mundo, com 5,9 milhões de cabeças, ficando atrás apenas do México e da China (FAO, 2003). O Estado do Rio Grande do Sul (RS) ocupa posição de destaque na criação de eqüinos no Brasil. Com o terceiro maior rebanho, aproximadamente 499 mil animais, o Estado contribui expressivamente com o agronegócio brasileiro (IBGE, 2003). A equideocultura brasileira apresenta uma ampla diversidade de finalidades exploratórias, cada qual com suas peculiaridades ecológicas, sanitárias e epidemiológicas. Essa diversidade dificulta o planejamento e o estabelecimento de normas sanitárias abrangentes e eficazes para os diferentes sistemas de criação.

As viroses estão entre as enfermidades de maior importância sanitária e econômica na eqüideocultura mundial, destacando-se a influenza, a arterite viral e as infecções herpéticas (TRAUBDARGATZ, 1993). A influenza eqüina (EI) é causada por um vírus RNA de polaridade negativa, envelopado, da família Orthomyxoviridae, gênero Influenzavirus $\boldsymbol{A}$ (MURPHY et al., 1999). O vírus replica principalmente no epitélio do trato respiratório superior, produzindo sinais respiratórios que variam em severidade e duração de acordo com a virulência da amostra viral, o manejo, as condições ambientais e as defesas do hospedeiro (WILSON, 1993). A enfermidade caracteriza-se por alta morbidade e baixa mortalidade. A EI apresenta distribuição mundial e é uma das principais doenças infecto-contagiosas dos eqüinos. O vírus da influenza já foi isolado no RS por BARROS \& WEIBLEN (1988) e vários estudos sorológicos sugerem a sua ampla distribuição no Brasil (LOUREIRO et al., 2000; OLIVEIRA et al., 2005).

$\mathrm{O}$ vírus da arterite eqüina (equine viral arteritis virus, EVAV), um vírus RNA de polaridade positiva pertencente à família Arteriviridae, tem sido associado a diversas manifestações clínicas em eqüinos, incluindo doença respiratória e morte súbita em potros, abortos e infecção branda ou subclínica em animais adultos (TIMONEY, 2003). Garanhões infectados tornam-se fonte de infecção e podem excretar o vírus no sêmen por longos períodos (DEL PIERO, 2000). Relatos clínicos e sorológicos indicam que a arterite viral está amplamente distribuída em populações eqüinas de todo o mundo (TIMONEY, 2003). $\mathrm{O}$ vírus da EVA ainda não foi isolado no Brasil, mas estudos sorológicos sugerem a sua circulação nos Estados de São Paulo (FERNANDES \& SOUZA, 1999; LARA et al., 2002) e Paraná (LARA et al., 2003).

O herpesvírus eqüino (EHV) é um vírus DNA, pertencente à família Herpesviridae, subfamília
Alphaherpesvirinae (MURPHY et al., 1999). Uma característica importante dos alfaherpesvírus é a capacidade de estabelecerem infecções latentes (OSTLUND, 1993). Infecções com o EHV podem resultar em doença respiratória, genital, aborto, em doença neonatal fatal e em síndromes neurológicas, dependendo do tipo viral. Os EHV-1 e EHV-4 (equine rhinopneumonitis virus) são antigenicamente relacionados e estão associados com doença respiratória e abortamento. O EHV-3 é o agente etiológico do exantema coital, caracterizado pela formação de vesículas no trato genital de machos e de fêmeas, não apresentando reatividade sorológica com os outros EHV (OSTLUND, 1993). O EHV-2 e o EHV-5 (equine cytomegalovirus) não têm sido consistentemente implicados em condições patológicas em cavalos (MURPHY et al., 1999). As fontes mais comuns de infecção do EHV são os animais idosos, que podem excretar o vírus nas secreções nasais após a reativação das infecções latentes (WEIBLEN, 2001). O impacto econômico da infecção pelos EHV pode ser significativo, principalmente devido à ocorrência de abortos epizoóticos. No Brasil, o primeiro isolamento do vírus foi descrito por NILSON \& CORRÊA (1966). Em Minas Gerais, CARVALHO et al. (1991) descreveram a ocorrência de abortos causados pelo EHV-1 em 15 éguas. WEIBLEN et al. (1994) relataram um surto de EHV-1 no RS. Em um estudo sorológico realizado em rebanhos com problemas reprodutivos no RS, VARGAS \& WEIBLEN (1991) detectaram 84,7\% de positividade entre as 348 amostras testadas para o EHV-1.

Os sistemas oficiais de saúde animal priorizam as doenças de interesse sanitário e comercial estratégico, sobretudo aquelas que afetam espécies de maior expressão econômica. Contudo, pouca ênfase tem sido dada à espécie eqüina e pouco se sabe sobre a ocorrência e a prevalência das principais viroses de eqüinos no RS e no Brasil. Este estudo teve por objetivo determinar a prevalência de anticorpos para os vírus da influenza, da arterite viral e do herpesvírus eqüino no Estado do RS.

\section{MATERIAL E MÉTODOS}

O estudo foi realizado com 1.506 amostras de soro oriundas de eqüinos de 65 municípios do Estado do Rio Grande do Sul. Essas amostras foram enviadas ao Laboratório de Virologia e Imunologia da Universidade de Passo Fundo (UPF) para o diagnóstico sorológico da infecção pelo vírus da anemia infecciosa eqüina (EIAV). Após a realização do teste requisitado, as amostras foram inativadas pelo calor $\left(56^{\circ} \mathrm{C}\right.$ por $\left.30 \mathrm{~min}\right)$ e distribuídas em duas alíquotas. Uma alíquota foi submetida ao teste de inibição da hemaglutinação (HI) 
para detectar anticorpos para o EIV e a outra foi remetida ao Setor de Virologia da UFSM, onde as amostras foram testadas por meio da técnica de soroneutralização (SN) para a detecção de anticorpos para os vírus da EVA e doEHV.

\section{Células e vírus}

O cultivo do EIV foi realizado em ovos embrionados. Para as técnicas de hemaglutinação (HA) e inibição da hemaglutinação (HI), foi utilizada uma suspensão de hemácias de galinha a $1 \%$ em solução salina fosfatada (PBS, pH 7,2). Os procedimentos de multiplicação, titulação e neutralização do EVAV e do EHV foram realizados em cultivo de células de linhagem de rim de coelho (RK-13). O cultivo das células foi realizado em meio essencial mínimo (MEM), contendo penicilina $\left(1,6 \mathrm{mg} \mathrm{L}^{-1}\right)$, estreptomicina $\left(0,4 \mathrm{mg} \mathrm{L}^{-1}\right)$ e nistatina $\left(0,02 \mathrm{mg} \mathrm{L}^{-1}\right)$ suplementado com $10 \%$ de soro fetal bovino (SFB). As cepas do vírus da influenza e do herpesvírus eqüino tipo 1 (Campinas) foram gentilmente cedidas pela Dra. Clarice Arns (Departamento de Microbiologia e Imunologia da Universidade de Campinas, Campinas, SP). A cepa Bucyrus do vírus da arterite viral eqüina foi adquirida do National Veterinary Laboratory Service (NVSL USDA, Iowa, USA).

Sorologia

O teste de HI, utilizado para a detecção de anticorpos para o EIV, foi realizado em placas de poliestireno de 96 cavidades, com fundo em " $U$ " (LOUREIRO et al., 2002). Previamente à realização do teste, as amostras de soro foram submetidas ao tratamento com caolin (25\% em PBS) para eliminação de inibidores inespecíficos da hemaglutinação (BALLOWS et al., 1996). Diluições crescentes do soro (fator de diluição 10) foram incubadas por uma hora a temperatura ambiente com quatro unidades hemaglutinantes (UHA) do vírus. Em seguida, foi adicionada a suspensão de hemácias de galinha (1\% em PBS) e, após incubação por $30 \mathrm{~min}$ a $4^{\circ} \mathrm{C}$, procedeuse a leitura. O título de anticorpos foi considerado a recíproca da maior diluição do soro capaz de inibir a hemaglutinação.

A SN, utilizada para a detecção de anticorpos para o EVAV e o EHV, foi realizada em placas de poliestireno de 96 cavidades (OIE, 1996). Resumidamente, diluições crescentes do soro (fator de diluição 2) foram incubadas com doses constantes dos vírus (100-200 doses infectantes para 50\% dos cultivos [DICC50] por cavidade da cepa Bucyrus [EVAV] ou Campinas [EHV-1], respectivamente). Após 90 min de incubação a $37^{\circ} \mathrm{C}$, foi adicionada a suspensão de células da linhagem RK-13. As placas foram incubadas em estufa a $37^{\circ} \mathrm{C}$ contendo $5 \%$ de $\mathrm{CO}_{2}$. A leitura dos resultados foi realizada após 72-96h de incubação, por meio do monitoramento do efeito citopático (ECP) nos cultivos celulares. O título neutralizante foi considerado a recíproca da maior diluição do soro capaz de prevenir a produção de ECP.

\section{RESULTADOS E DISCUSSÃO}

No presente estudo, foram analizadas amostras de soro eqüino enviadas ao Laboratório de Virologia e Imunologia da UPF entre os anos de 2003 e 2004 para diagnóstico sorológico da anemia infecciosa eqüina (EIA). O teste sorológico negativo para o EIAV é obrigatório para a obtenção de guia de transporte animal (GTA). A coleta e a submissão das amostras de soro é de responsabilidade de médicos veterinários e as amostras devem ser acompanhadas de resenhas detalhadas dos animais. Os dados contidos nas respectivas resenhas foram tabulados e utilizados para a análise e apresentação dos resultados do presente estudo.

Dentre as amostras enviadas, a grande maioria (1.334 ou 88,5\%) foi proveniente de animais utilizados para esporte. No Estado do Rio Grande do Sul, as principais atividades esportivas que utilizam eqüinos são os rodeios e as carreiras. Atividades de hipismo (saltos) e ecoturismo (cavalgadas) ocupam uma posição secundária. Exposições e leilões também são eventos de ocorrência freqüente e que exigem a GTA. Animais de exposição, sobretudo da raça crioula, contribuíram com 6,3\% (94) das amostras e os animais de reprodução com 5,2\% (78). As fêmeas contribuíram com $61,1 \%$ (920) das amostras e os machos com 38,9\% (586). As amostras foram provenientes de 65 municípios, em sua grande maioria pertencentes à região norte do RS (Figura 1a). Os municípios que contribuíram com maior número de amostras foram: Passo Fundo (845 - 56,1\%), São José do Ouro (82 5,4\%), Marau (69-4,5\%), Erechim (50 - 3,3\%) e Lagoa Vermelha (43 - 2,8\%). Do total de amostras testadas, $72,1 \%$ foram provenientes desses cinco municípios. Por isso, as amostras podem ser consideradas representativas especialmente da população eqüina dessa região, respeitadas as ressalvas mencionadas adiante.

Das 1.506 amostras testadas, $986(65,4 \%)$ apresentaram anticorpos para o EIV, 33 (2,2\%) apresentaram anticorpos contra o EVAV e 67 (4,5\%) reagiram contra o EHV (Tabela 1). Apesar da existência de vacinas comerciais para o vírus da influenza (EIV) e para o herpesvírus (EHV) no Brasil, a prevalência detectada provavelmente seja devida à circulação 


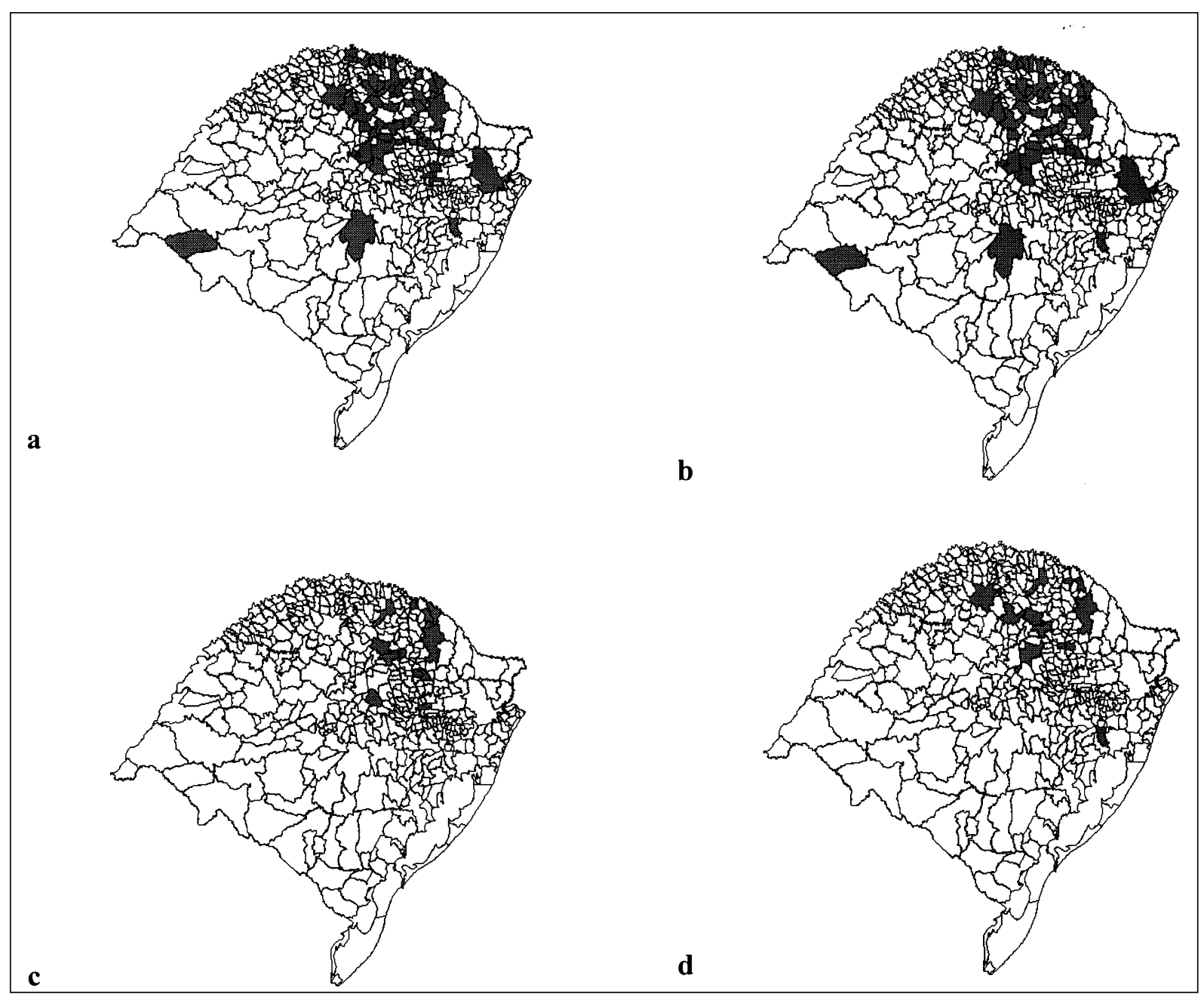

Figura 1 - Mapa do Rio Grande do Sul representando os municípios amostrados (a); os municípios com animais positivos para os vírus da influenza eqüina (EIV) (b); da arterite viral eqüina (EVAV) (c); e herpesvírus eqüino (d).

desses agentes na população estudada. Dois aspectos fortalecem essa hipótese: i. as vacinas para esses agentes foram introduzidas apenas recentemente no país e seu uso ainda é bastante restrito, e ii. a maioria das amostras foi proveniente de animais de propriedades em que a eqüideocultura é a atividade secundária, nas quais a vacinação para esses agentes é pouco freqüente. Informalmente, sabe-se que a vacinação para o EIV e para o EHV ocorre há vários anos, sobretudo em haras de criação de cavalos puro sangue inglês (PSI). No entanto, animais dessa categoria contribuíram com poucas amostras nesse estudo e conseqüentemente não alteraram a interpretação dos resultados.

A influenza eqüina é uma enfermidade caracterizada por rápida disseminação e alta morbidade, quando introduzida em rebanhos susceptíveis (WEIBLEN, 2001). Essas características podem explicar a ampla disseminação do EIV na população eqüina do Brasil, já demonstrada por meio do isolamento do agente (BARROS \& WEIBLEN, 1988) e por vários estudos sorológicos (LOUREIRO et al., 2000; SILVA et al., 2003; OLIVEIRA et al., 2005). A prevalência de 65,4\% (com título de anticorpos entre 10-1.280) detectada no presente estudo e a detecção de pelo menos um animal reagente ao EIV em 55 municípios amostrados (84,6\%) sugerem a ampla disseminação do agente também no rebanho eqüino do RS (Figura 1b). Como já mencionado, o uso da vacinação para o EIV no rebanho estudado ainda é incipiente e restrito. Por isso, a maior parte da prevalência detectada provavelmente seja devida à infecção natural. A elevada prevalência pode ser atribuída à rápida disseminação do agente entre animais susceptíveis, aliada ao trânsito intenso e à aglomeração de animais de diversas procedências em provas esportivas, leilões/exposições ou para reprodução. 
Tabela 1 - Prevalência de anticorpos para os vírus da influenza (EIV), da arterite viral (EVAV) e do herpesvírus eqüino (EHV) em eqüinos do Estado do Rio Grande do Sul.

\begin{tabular}{|c|c|c|c|c|}
\hline & & \multicolumn{3}{|c|}{ Positivos (\%) } \\
\hline & & Influenza (EIV) & Arterite viral (EVAV) & Herpesvírus (EHV) \\
\hline \multirow[t]{3}{*}{ Propósito } & Esporte $^{1}$ & $857(64,2)$ & $28(2,0)$ & $55(4,1)$ \\
\hline & Exposição & $74(78,7)$ & $2(2,1)$ & $6(5,3)$ \\
\hline & Reprodução & $55(70,5)$ & $3(3,8)$ & $6(6,4)$ \\
\hline \multirow[t]{2}{*}{ Sexo } & Macho & $385(65,6)$ & $15(2,5)$ & $28(4,7)$ \\
\hline & Fêmea & $601(65,3)$ & $18(1,9)$ & $39(4,2)$ \\
\hline \multirow[t]{3}{*}{ Total } & Positivas & $986(65,4)$ & $33(2,2)$ & $67(4,5)$ \\
\hline & Título & $10^{2}-1280^{3}$ & $2^{2}-16^{3}$ & $2^{2}-64^{3}$ \\
\hline & Negativas & $520(34,6)$ & $1473(97,8)$ & $1439(95,5)$ \\
\hline $\mathrm{N}$ & & 1506 & 1506 & 1506 \\
\hline
\end{tabular}

${ }^{1}$ Inclui animais utilizados para rodeio, hipismo e montaria.

${ }^{2}$ Menor título de anticorpos detectado.

${ }^{3}$ Maior título de anticorpos detectado.

Neste contexto, fica evidente a necessidade de se adotar medidas preventivas, como quarentena ou triagem sorológica/virológica, para as principais doenças infectocontagiosas anteriormente a esses eventos. A adoção de tais medidas minimizaria o risco de disseminação dessas enfermidades no rebanho eqüino e os prejuízos decorrentes da infecção(WILSON, 1997).

Anticorpos para o EVAV foram detectados em 15 (23\%) dos 65 municípios amostrados, com cada município apresentando pelo menos um animal reagente (Figura 1c). Apesar do EVAV ainda não ter sido isolado no Brasil, a detecção de anticorpos para esse agente em São Paulo (FERNANDES \& SOUZA, 1999; SOUZA et al., 1999; LARA et al., 2002) e no Paraná (LARA et al., 2003) sugere a sua circulação no rebanho eqüino desses Estados. Da mesma forma, a prevalência de anticorpos para o EVAV detectada no presente estudo sugere que o vírus está presente no rebanho eqüino do RS. Embora numericamente baixa (2,2\%, com títulos variando entre 2-16), a prevalência de anticorpos para o EVAV detectada merece atenção especial, pois envolve animais submetidos a transporte e aglomeração, o que pode favorecer a disseminação do agente. Algumas características epidemiológicas da infecção pelo EVAV, como a ocorrência de infecções subclínicas e a possibilidade de garanhões infectados permanecerem portadores (DEL PIERO, 2000), podem contribuir para a sua disseminação. A maior prevalência de anticorpos para o EVAV no Estado de São Paulo (FERNANDES \& SOUZA, 1999) pode ser atribuída às características dos rebanhos e das amostras testadas, uma vez que foram utilizadas amostras provenientes de propriedades com problemas reprodutivos e/ou respiratórios. Em alguns países, onde a criação e o trânsito de eqüinos para a realização de provas hípicas é intenso, a prevalência de anticorpos para o EVAV também é mais elevada (NOSETTO et al.,1984; McCUE et al., 1991).

O herpesvírus eqüino (EHV) apresenta-se amplamente distribuído na população eqüina do Brasil, tendo sido isolado pela primeira vez por NILSON \& CORRÊA (1966), em São Paulo. WEIBLEN et al. (1994) relataram a ocorrência de um surto de abortos causado pelo EHV em propriedades do RS e MOREIRA et al. (1998) detectaram o EHV-1 em 8\% dos casos de aborto eqüino em SP. Além do isolamento viral, a detecção de anticorpos para o EHV confirma a disseminação do agente no rebanho eqüino brasileiro (VARGAS \& WEIBLEN, 1991; MOREIRA et al., 2000; CUNHA et al., 2002; HEINEMANN et al., 2002). A detecção de anticorpos para o EHV (títulos entre 2 e 64) em 67 animais (4,5\%) no presente estudo confirma a circulação do agente na população eqüina do Estado. Em 12 municípios amostrados (18,5\%), foi detectado pelo menos um animal reagente ao EHV (Figura 1d). A prevalência relativamente baixa pode ser atribuída às características epidemiológicas das amostras testadas, pois foram provenientes de animais hígidos e em sua maioria de criações semi-intensivas. No entanto, a importância epidemiológica desses achados deve ser ressaltada, pois a soropositividade - com exceção de sorologia vacinal - indica a condição de portador de infecção latente (OSTLUND, 1993). O EHV é responsável por prejuízos econômicos significativos em locais onde a infecção é endêmica e em países onde a eqüideocultura constitui-se em um importante ramo do agronegócio (OIE, 1996).

As características epidemiológicas das amostras testadas merecem algumas considerações. As 1.506 amostras testadas não foram extraídas da população por métodos estatísticos. Por isso, tais 
amostras não podem ser consideradas estatística e epidemiologicamente representativas da população de origem. Por outro lado, essa parcela da população também não pode ser considerada uma amostra viciada. Os animais testados representam uma parte da população eqüina da região (e de suas respectivas criações) que foi transportada durante o período, por diferentes finalidades. O fato de terem sido transportados é que os levou a serem incluídos na amostragem. Qualquer análise epidemiológica mais aprofundada deve considerar esses aspectos.

Dentre os componentes da amostra podese evidenciar pelo menos duas situações epidemiológicas, com fatores e nível de risco distintos: 1. os animais que são transportados com freqüência e 2. aqueles animais que foram/são transportados apenas ocasionalmente. Os animais do primeiro grupo estão continuamente expostos ao risco de serem infectados, pela sua participação em rodeios, carreiras, provas de função, leilões, etc. Nessas ocasiões, convivem com animais de diversas procedências, o que os expõe ao risco de infecção com agentes infecciosos. Os demais animais (grupo 2), mesmo sendo transportados ocasionalmente, também apresentam esse fator de risco, pois nessas exposições eventuais a outros animais e a agentes infecciosos pode ocorrer a infecção. No entanto, o risco de infecção do segundo grupo é menor, uma vez que não são rotineiramente transportados e não participam desses eventos com tanta freqüência. Teoricamente, os animais do primeiro grupo deveriam apresentar índices de soropositividade superiores quando comparados com o segundo. Infelizmente, informações referentes à freqüência de transporte e a participações nesses eventos não estavam disponíveis nas resenhas individuais. Não obstante, esses aspectos devem ser necessariamente considerados quando da interpretação dos resultados obtidos. Ou seja, os valores de soropositividade detectados podem ser considerados parcialmente representativos da população eqüina da região, pois são relativos à parcela de animais dessas criações que é transportada esporádica ou freqüentemente.

Em resumo, os resultados do presente estudo sugerem a presença do EIV, do EVAV e do EHV no rebanho eqüino do Estado do RS. A possível circulação desses agentes alerta para a necessidade de estudos adicionais sobre a importância sanitária e econômica dessas infecções para a eqüideocultura do Estado. Além disso, fica evidente a necessidade de se realizar um maior controle sanitário no transporte, nas exposições, feiras e competições esportivas que envolvem animais de diversas procedências, com a finalidade de minimizar a disseminação de agentes infecto-contagiosos e reduzir os prejuízos econômicos ocasionados por estes.

\section{AGRADECIMENTOS}

Ao Conselho Nacional de Desenvolvimento Tecnológico (CNPq) e ao Finep (PRONEX em Virologia Veterinária, 215/96), pelo suporte financeiro e pelas bolsas de mestrado (Diego Gustavo Diel e Sabrina Ribeiro de Almeida) e de iniciação científica (Denis Anziliero). Rudi Weiblen (301339/ 2004-0), Eduardo Furtado Flores (301666/2004-0) e Luiz Carlos Kreutz (300259/2003-4) são bolsistas PQ do CNPq.

\section{REFERÊNCIAS}

BARROS, C.S.L.; WEIBLEN, R. Centro de diagnóstico veterinário. Santa Maria: Universidade Federal de Santa Maria, 1988. 60p. (Boletim Técnico).

BALLOWS, A. et al. Manual of clinical microbiology by American Society for Microbiology. 5.ed. Washington: ASM, 1996. $874 \mathrm{p}$.

CARVALHO, F.S.R. et al. Aborto eqüino por herpesvírus equi 1. Rev Ciênc Biom, v.7, n.1, p.45-47, 1991.

CUNHA, E.M.S. et al. Presença de anticorpos para o herpesvírus eqüino 1 (HVE-1) em eqüinos do noroeste do estado de São Paulo. Arq Inst Biol, v.69, n.1, p.1-5, 2002.

DEL PIERO, F. Equine viral arteritis. Vet Pathol, v.37, p.287-296, 2000.

FAO. Agricultural Data - FAOSTAT, 2003. Capturado em 15 jan. 2005. Online. Disponível na Internet http:// faostat.fao.org/faostat/collections?subset=agriculture.

FERNANDES, W.R.; SOUZA, M.C.C. Determinação sorológica da arterite viral eqüina em eqüinos hígidos, com abortamento e com sintomas de alteração do sistema respiratório. Rev Bras Ciênc Vet, v.6, n.3, p.147-150, 1999.

HEINEMANN, M.B. et al. Soroprevalência da anemia infecciosa eqüina, da arterite viral dos eqüinos e do aborto viral eqüino no município de Uruará, PA, Brasil. Braz J Vet Res Anim Sci, v.39, n.1, p.50-53, 2002.

IBGE. Pesquisa Pecuária Municipal, 2003. Capturado em 18 ago. 2005. Online. Disponível na Internet http:// www.sidra.ibge.gov.br/bda/tabela/listabl.asp?c $=73 \& \mathrm{z}=\mathrm{t} \& \mathrm{o}=20$.

LARA, M.C.C.S.H. et al. Prevalência de anticorpos antivírus da arterite dos eqüinos em cavalos criados no estado de São Paulo. Arq Bras Med Vet Zoot, v.54, n.3, p.223-227, 2002.

LARA, M.C.C.S.H. et al. Pesquisa de anticorpos para o vírus da arterite dos eqüinos (VAE) e herpesvírus eqüino tipo 1 (HVE-1) em cavalos criados em Curitiba, PR. Hor Vet, v.23, n.135, p.51-53, 2003.

LOUREIRO, B.O. et al. Seroepidemiology of the virus of equine influenza, subtype A/equine-2 (H3N8), in the Rio de Janeiro's State - Brazil, São Lourenço, MG, 2000. In: NATIONAL MEETING OF VIROLOGY 11., MERCOSUL MEETING OF VIROLOGY, 2000, São Lourenço, MG. Anais... São Paulo: Virus: Reviews and Research/Sociedade Brasileira de Virologia, 2000. V.5, n.2, 210p. p.152. 
LOUREIRO, B.O. et al. Soroepidemiologia da influenza eqüina, subtipo A/Eqüino-2 (H3N8) no Estado do Rio de Janeiro. Rev Bras Med Vet, v.24, n.1, p.11-13, 2002.

McCUE, P.M. et al. Prevalence of equine viral arteritis in California horses. Calif Vet, v.45, n.2, p.24-26, 1991.

MOREIRA, N. et al. Aspectos etiológicos e epidemiológicos do aborto eqüino. Arch Vet Sci, v.3, n.1, p.25-30, 1998.

MOREIRA, N. et al. Freqüência de anticorpos neutralizantes para o herpesvírus eqüino tipo 1. Scient Agrar, v.1, n.1-2, p.9-14, 2000

MURPHY, F.A. et al. Veterinary virology. 3.ed. San Diego: Academic, 1999. 629p.

NILSON, M.R.; CORRÊA, W.M. Isolamento do vírus do aborto eqüino no estado de São Paulo. Arq Inst Biol, v.33, p.23-35, 1966.

NOSETTO, E.O. et al. Arteritis viral equina: detección de anticuerpos en equinos de la Republica Argentina. Zentr Veter B, v.31, n.7, p.526-529, 1984

OIE. Equine rhinopneumonitis. In: Manual of standars for diagnostic tests and vaccines. 3.ed. Paris: OIE - Paris, 1996. Cap.3.4.7, p.426-433.

OLIVEIRA, G.S. et al. Prevalência de anticorpos para o vírus da influenza eqüina, subtipo H3N8, em eqüideos apreendidos no estado do Rio de Janeiro. Ciênc Rural, v.35, n.5, p.12131215,2005

OSTLUND, E.N. The equine herpesvirus. In: TRAUB DARGATZ, J.L. The Veterinary Clinics of North America: Equine Practice. London: Saunders, 1993. v.9, n.2, p.283294

SILVA, A.J. et al. Antibodies against equine influenza virus in the mata mineira region, Florianópolis, SC, 2003. In:
NATIONAL MEETING OF VIROLOGY 14., 2003, Florianópilos, SC. Anais... São Paulo: Virus: Reviews and Research/Sociedade Brasileira de Virologia, 2003. V.8, 278p. p.153-154.

SOUZA, M.C.C. et al. Pesquisa de anticorpos para o vírus da arterite dos eqüinos criados no Vale do Paraíba. Arq Inst Biol, v.66, p.40, 1999.

TIMONEY, P.J. Arteritis viral equina. International Veterinary Information Service, 2003. Capturado: 20 mar. 2005. Online. Disponível na Internet http://www.ivivs.org/ special_book/lekeux/timoney/chapter_frm.asp?LA=1

TRAUB-DARGATZ, J.L. The Veterinary Clinics of North America: Equine Practice. London: Saunders, 1993. V.9, 448p.

VARGAS, A.C.; WEIBLEN, R. Prevalência de anticorpos para herpesvirus eqüino tipo 1 (HVE-1) em eqüinos de alguns municípios do estado do Rio Grande do Sul. Hor Vet, v.10, p.58, 1991.

WEIBLEN, R. Influenza eqüina. In: RIET-CORREA, F.et al. Doenças de ruminantes e eqüinos. São Paulo: Varella, 2001. V.1, p.121-125.

WEIBLEN, R. et al. Abortion due to equine herpesvirus in southern Brazil. Braz J Med Biol, v.27, p.1317-1320, 1994.

WILSON, D.W. Equine influenza. In: TRAUB-DARGATZ, J.L. The Veterinary Clinics of North America: Equine Practice. London: Saunders, 1993. V.9, p.257-282.

WILSON, D.W. Equine herpesvirus 1 myeloencephalopathy. In: TRAUB-DARGATZ, J.L. The Veterinary Clinics of North America: Equine Practice. London: Saunders, 1997. V.20, p.53-72 